Article

\title{
Ethical Leadership, Affective Commitment, Work Engagement, and Creativity: Testing a Multiple Mediation Approach
}

\author{
Muhammad Asif ${ }^{1}{ }^{\mathbb{D}}$, Miao Qing ${ }^{1, *}$, Jinsoo Hwang ${ }^{2, *}$ and Hao Shi ${ }^{1}$ \\ 1 School of Public Affairs, Zijingang Campus, Zhejiang University, Hangzhou 310058, China \\ 2 The College of Hospitality and Tourism Management, Sejong University, 98 Gunja-Dong, Gwanjin-Gu, \\ Seoul 143-747, Korea \\ * Correspondence: mqok@163.com (M.Q.); jhwang@sejong.ac.kr (J.H.)
}

Received: 11 July 2019; Accepted: 16 August 2019; Published: 19 August 2019

check for updates

\begin{abstract}
This study aimed to explore the relationships among ethical leadership (EL), affective commitment (AC), work engagement (WE), and employees' creativity (EC). In total, 233 Chinese public sector employees completed the survey in three phases. We used confirmatory factor analysis (CFA) and structural equation modeling (SEM) to analyze the data. The paper found positive relationships between EL and WE and with EL and EC. The results further revealed that AC partially mediates the EL-WE relationship, while both AC and WE fully mediate the relationship between EL and EC. Testing these relationships via a multiple-mediated approach significantly contributed to the existing research on leadership.
\end{abstract}

Keywords: ethical leadership; affective commitment; work engagement; employee creativity; structural equation modeling (SEM)

\section{Introduction}

With significant and rapid technological, cultural, demographic, and economic changes in our knowledge-based economy, employee creativity has become an increasingly crucial challenge for organizations to develop employees, enhance the core competence of the organization $[1,2]$, and help organizations not only survive but also maintain sustainable competitive advantage in the global market [3-5]. Naturally, organizations increasingly seek different ways to foster employee creativity [6,7]. The quest to understand effective leadership has become one of the most important goals and common aspiration for researchers, individuals, organizations, and societies around the world.

In recent years, ethical scandals across the world have drawn the attention of researchers toward the study of ethical leadership (EL), and the organizations are also trying to seek the proper mechanisms to redress their leader's unethical behaviors and to enhance the integrity and social responsibility [8]. Earlier research points out that EL has a significant and optimistic association with several sustainable aspects of leadership effectiveness, which comprise of workers' engagement, job satisfaction, organizational citizenship behavior (OCB), and the performance and commitment to the organization [9-12]. Likewise, successful organizations regard employees' work engagement (WE) as one of the most important elements for their survival [13] and improved organizational performance [14]. Employees' WE is connected with positive institutional and individual outcomes, such as improvement of productivity and organizational citizenship behavior, job satisfaction, and strengthening managerial efficiency and effectiveness [15]. In contrast, these individual and organizational outcomes decrease with employees' dis-engagement [13]. On the other hand, employee creativity (EC), in today's world, is increasingly believed to be the core organizational competence and needs to be enhanced among 
employees through proper training and adequate experience [16]. For that reason, scholars link EC with organizational success $[3,6]$, and organizations are aiming to identify the right ways to promote creativity among their employees [17].

Leadership is the most influential element of WE and EC because leaders establish a healthy work environment where employees feel more motivated and self-satisfied with the help of their positive behaviors [13,18]. Relatedly, EL has also a positive impact on WE [19] and EC [20]. According to Feng, et al. [21], WE will be improved when ethical leaders demonstrate supportive behaviors and build a healthy environment through the means of proper feedback, trustworthiness, interactional justice, fair decision making, and care. These supportive behaviors help them to be involved in organizational creative tasks and increased their creativity [18]. According to Blau [22], when a working group performs their job, which is beneficial or valuable for another group, then the other group will endeavor to reciprocate equally, in return. This will establish a reciprocal relationship between leaders and their followers [13]. Consistently, employees feel more obliged and engaged in the organization when ethical leaders enable them with socio-emotional resources [23]. This may also increase the positive perceptions of employees for their leaders. Moreover, support from ethical leaders enhance the morality level among employees, and they put in extra effort to achieve sustainable organizational goals with full obligation, which actually demonstrate their greater AC [24] and engagement [21]. Relevant to the present research, only some empirical research has demonstrated the association between EL and EC through different mediators, such as voice behavior [25], LMX and psychological empowerment [20]. More research is needed to develop a better comprehension of this relationship. Therefore, we proposed to further explore the impact of EL on EC with different contexts in a non-western culture.

Cultural background and how employees interact with the leader should also be studied. Leadership styles need to be adapted to different environments and cultures in order to have an effective impact [26]. Hofstede [27] divided different groups of nations into various culture clusters where each has its own characteristics due to the history, culture, and tradition of the country. Resick, et al. [28] further labeled the Asian countries as the Asian Confucius cluster that shared the common traits of collectivism, team orientation, and harmonious relationships. Out of the Asian Confucius cluster, China seemed to be the most influenced by the Confucian ideology where workplaces were shaped into close hierarchy relationships, with the subordinates having great respect and honor to the leaders as a child would behave to a father. For other Asian countries, which had a stronger influence on Western business cultures such as Hong Kong or Taiwan, that demonstrated some characteristics similar to the U.S. respondents, the overall behavior and perception of employees' ethics were still shaped and impacted by traditional Chinese values. Hence, we have made an effort to investigate EL-EC relationship in the Chinese context using AC and WE as the potential mediators.

The research adds to the literature review in different ways. Firstly, it enabled us to determine whether employees EC and WE were intensified by EL within the institutionally bound culture, for example, to what extent is this EL successful in encouraging certain work behaviors in the Chinese government sector. Second, this research strengthens the present EL literature by seeking innovative contexts, which might have a distinct impact on followers' outcomes. We attempted to develop a contributory mechanism of how EL works through AC and WE to promote EC in subordinates. Although, some other studies used different mediators to test this relation, for example, psychological empowerment [19] and trust in leaders [29]. Third, we investigated the mediation effect of AC on the association between EL and WE. Since most leadership studies are based on Western culture. Researchers have recognized the impact of national culture on influencing leadership attributes and effectiveness [26,30], yet no research has explicitly investigated the relationships between ethical leadership and employee creativity using above mentioned mediators that are specific in the Chinese cultural context. 


\section{Theory and Hypotheses}

Figure 1 illustrates the hypothesized research framework where the direct effects of ethical leadership on work engagement and employee creativity were examined first, and then other relationships and indirect effects among ethical leadership, affective commitment, work engagement, and employee creativity were investigated.

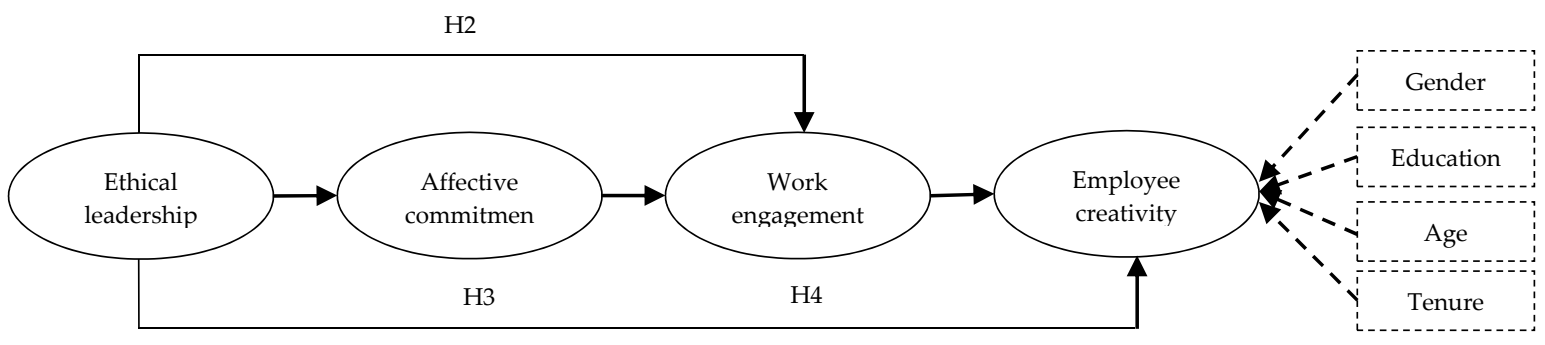

H1

Figure 1. Hypothesized model.

\subsection{Ethical Leadership and Employee Creativity}

Ethical leadership is defined as "the demonstration of normatively appropriate conduct through personal actions and interpersonal relationships, and the promotion of such conduct to subordinates through two-way communication, reinforcement, and decision-making" [31]. In other words, this definition highlights three main characteristics of an ethical leader: he or she is the one who (a) practices what he or she preaches, (b) believes in justice, and (c) communicates meaningful information.

Differential association theory may address the first component of the ethical leader's characteristics (i.e., practicing what he or she preaches). It states that employees learn moral or immoral conduct while working with their colleagues and leaders [32]. Research has also found that the influence of ethical values of superiors on subordinates outweighs that of peers [33] because workers have a tendency to go along with their superiors' moral decisions to exhibit loyalty [32]. Social learning theory points out that this ethical influence takes place through a role-modeling process [34,35]. It can be achieved when leaders participate in behaviors that advance the well-being of others and abstain from behaviors that may cause damage to others [10]. These leaders may use several strategies to empower their subordinates, enhance their potency, and modify their values, norms, and attitudes to align with their organization's and community's standards.

Organizational justice theory, developed by Greenberg [36] and modified by Colquitt [37], may address the second component of the ethical leader's characteristics (i.e., believing injustice). It argues that an employee judges the behavior of the leader and reacts accordingly. The judgment and the reaction go through four stages: distributive, procedural, interpersonal, and informational. Employees first evaluate the fairness associated with the distribution of resources that could be tangible, such as pay increase, or intangible, such as recognition, in the distributive stage. If they perceive that such distribution is equitable, then the perception of justice prevails. Employees then question the process that leads to the decision to distribute a pay increase or recognition in the procedural stage. If they feel that the process is consistent, ethical, unbiased, and inclusive of their voices, then their perceptions of justice are enhanced. In the third interpersonal stage, employees judge their leader's behavior toward them. If the leader treats them with politeness, dignity, and respect, then their satisfaction is furthered. Finally, employees shift to a higher stage of evaluation: the informational stage. They judge the leader's explanations of his or her decisions. If the leader is truthful, specific, and timely in providing information, such as why a pay increase is distributed in a certain way, then employees are content.

As organizational actions and/or decisions of leaders are perceived as just, employees are more likely to participate in cooperative behaviors in which they support the organization beyond the scope 
of their job description. Research has found that cooperative behaviors are in turn strongly related to opportunities for creativity [38].

In conclusion, ethical leaders respect and tolerate employees' divergent views and values through their advancement of trust, honesty, consideration, virtuousness, and fairness within their relationships [39]. They shape and affect corporate culture, encourage the autonomy of employees, and value their ideas [40], which boosts employees' creativity [41]. In fact, several researchers have reported that honest leaders do not avoid uncertainty by allowing their subordinates to take risks, and hence, be more creative [42-44]. Based on the above theories and research findings, we propose the following hypothesis:

Hypothesis 1 (H1). EL will be positively related to EC.

\subsection{Ethical Leadership and Work Engagement}

In a broader way, EL can be described as "the demonstration of normatively appropriate conduct through personal actions and interpersonal relationships, and the promotion of such conduct to followers through two-way communication, reinforcement, and decision-making" [31]. Basically, ethical leaders behave like a moral individual and a moral supervisor at the same time. The aspect of the moral personality of an ethical leader referred to specific features which are based on his credibility, honesty, and integrity. Contrarily, the function of an ethical leader as a moral supervisor included the impartial and rational decision making, communicate the expected links with the achievement of sustainable organizational goals, and take care of employees' well-being [45]. Ethical leaders have an adaptive nature to follow the moral decision rules in their personal and professional lives and, thus, behave accordingly. These types of characteristics shape their personalities further making them more cherished and eye-catching [9]. In line with Qing, et al. [46], the impact of EL on followers' work-related attitudes is quite different as compared to other leadership theories.

Employees' WE is a 3-dimensional (vigor, dedication, and absorption) inspirational approach. The element of vigor refers to the willingness to put efforts in work. The dedication dimension refers to significance, pride, enthusiasm, inspiration, and challenge from work, while absorption captures the characteristics of being concentrated and complete engagement in work [47]. Mauno, et al. [48] noted that vigor has conceptual similarity with the concept of work motivation, whereas dedication relates more to the concept of job involvement. These elements of engagement seem especially relevant to the ethical leadership process. Ethical leadership that makes work more significant and meaningful to followers is likely to enhance their dedication to this work and their willingness to invest and persist even when things are difficult [40]. Hence, Den Hartog and Belschak [49] suggested that the impact of ethical leaders on followers comes about through enhancing this positive motivational state of engagement (and especially vigor and dedication). Since WE facilitates employees by motivating and encouraging their dynamic emotions towards their organization [50]. It enhances higher energy levels, participation, and employees' commitment $[24,51]$ and enthusiasm about their work, with a focus to achieve individual and organization goals [52].

Besides, Macey, et al. [53] argue that employees will engage in their work when they know what the strategic priorities of the organization are, and how they contribute to the company's goals through their work. Ethical leaders care about their followers and engage in frequent communication with their employees [9]. These leaders take their followers into consideration and, through frequent communication, make it clear what the organization's goals are and what is expected of them. Based on these arguments, it can be hypothesized that:

Hypothesis 2 (H2). EL will be positively related to employees' WE. 


\subsection{The Mediating Role of Affective Commitment and Work Engagement}

In a broader sense, EC is more valuable, because it is linked to organizational change. It provides new solutions and innovative mechanisms to understand the change phenomenon that leads to efficiency and the survival of the organization $[18,54]$. It is a significant way that workers can express their capabilities as human beings [20]. Similarly, AC is related to the employees' WE in two contexts. First, when the employees have a strong commitment, they believe more obligation and involvement in the organizational activities and achieve organizational goals with harder work [55]. They feel greater engagement equally in-role and additional-role useful behaviors [56]. Second, AC encourages employees in developing progressive attitudes toward the specific tasks aimed at being achieved [57]. Employees give more value to those tasks, show more willingness to exert extra effort and try to improve their performance to stay with the organization. Their desire to maintain their role in the organizations increases their level of engagement and improves performance $[14,58]$.

According to Amabile and Pratt [6] and Binnewies, et al. [59], innovative thoughts and problem solutions are produced by those individuals who are closely linked to the organization. Moreover, committed employees have the abilities to tackle the barriers and achieve their goals with fewer resources [60]. These abilities affect their attitude and make them more engaged, self-confident, productive, optimistic, practical, and victorious in sustainable goal achievement and problem solving $[60,61]$. Highly engaged employees can easily deal with anxiety, which enables them to be more determined with their work and show creative behavior [62]. When these motivated employees show creative behavior with their work, they receive appreciation and respect from their leaders, team members, and even from the customers in return [18]. Consequently, they possess auspicious behavior connected with their jobs, which allows them to become extra passionate and productive [63,64].

Since ethical leaders seek to meet employees' socio-emotional needs in the organization, employees feel attached to the organization, and thereby, more involved in activities to achieve organizational goals [55]. Thus, when employees perceive that their opinions and inputs are genuinely valued by ethical leaders, they feel secure enough to maintain their job in the organization [46], which means that they have formed a strong affective organizational commitment. In addition, ethical leadership causes employees to be more engaged in their work via strong affective organizational commitment. Supportive behaviors of ethical leaders, such as openness to input from employees and willingness to provide resources for employees, may enhance employee engagement [29] which ultimately leads to employee creativity [21]. These positive exchanges between ethical leaders and employees provide the employees with opportunities to develop expertise, cognitive thinking, and motivation to participate in creative work [20]. In addition, leaders having ethical behaviors provide their followers a healthy environment which enables them to be more committed and engaged also lead to the forming of positive affect among employees, which helps to shape conditions for employees that will be conducive to coming up with novel and creative ideas [21,65]. Based on these arguments we predicted:

Hypothesis 3 (H3). AC mediates the effect of EL on employees' WE.

Hypothesis 4 (H4). Both AC and WE mediate the effect of EL on EC.

\section{Materials and Methods}

\subsection{Participants and Procedure}

The present study used data obtained from full-time government sector workers that work in the Zhejiang province of China. We translated the questionnaires into the Chinese language from English before distribution and then re-translated them accordingly [66]. In total, 351 Masters in public administration (MPA) alumni were randomly chosen from the databank of Zhejiang University Hangzhou in China. All participators were approached directly in place of their institution and 
confidentiality was also assured. After their partaking permission, an online link where to access the survey was e-mailed to them in three different phases over a two months gap. These measures were adopted to decrease CMV [67]. Firstly, workers provided their demographic details, which included age, gender, education, and tenure, and to evaluate the EL behavior of their current supervisor. In the second phase, AC and WE were measured by the followers, and EC was evaluated by the supervisors in the third phase. In total, 233 personnel answered the surveys organized in all phases. The true response ratio was of $66 \%$. There were 123 male $(53 \%)$ and 110 female $(47 \%)$ respondents. About $71.25 \%$ of the employees were less than 40 years old, and $69 \%$ of them had been performing duties for less than five years under their present supervisor.

\subsection{Common Method Variance Issue}

The common method variance (CMV) [67] is a potential threat to the validity of research findings. We collected data from separate phases for the criterion (EC) and predictor (EL, AC, and WE) variables to avoid the possible CMV effects in this study. We tested the CMV issue in two steps.

First, we used Harman's single-factor test. Significant CMV exists, if one general factor accounts for the majority of covariance in the measures. Results of our exploratory factor analysis (EFA) using all variables in this study yielded four factors with eigenvalues greater than one that accounted for 67.03 percent of the total variance and the first factor accounted for 21.03 percent of the variance. Therefore, a single factor did not emerge, and one factor did not account for most of the variance.

Second, we compared (1) the measurement model with the addition of an unmeasured latent CMV factor $\left(\chi^{2}=581.07, \mathrm{df}=374, p=0.00, \chi^{2} / \mathrm{df}=1.55, \mathrm{IFI}=0.92, \mathrm{TLI}=0.91, \mathrm{CFI}=0.92, \mathrm{RMSEA}=0.06\right)$ and (2) the same measurement model without the CMV factor $\left(\chi^{2}=694.93, \mathrm{df}=406, p=0.00, \chi^{2} / \mathrm{df}=1.71\right.$, $\mathrm{IFI}=0.90$, TLI $=0.90, \mathrm{CFI}=0.90, \mathrm{RMSEA}=0.06)$, and found that the changes of the fit indies were not significant $(\triangle \mathrm{TLI}=0.01, \triangle \mathrm{RMSEA}=0.00$, respectively). Since this measurement model did not significantly improve the fit over our measurement model without a CMV factor, the CMV was not a problem [68]. Our solid measurement properties enhanced our confidence in testing our hypothesized relationships.

\subsection{Measures}

All survey items were measured using a 5-point Likert's scale, which ranged from strongly agree to strongly disagree.

EL was assessed using the 10 items ethical leadership scale (ELS) established by Brown et al. [31]. A sample item for EL included: My supervisor conducts his/her personal life in an ethical manner. The $\alpha$ value for EL was observed at 0.86 . AC was assessed using a 6 item scale established by Meyer et al. [69]. A sample question included: I would be happy to spend the rest of my career with this organization. The alpha $(\alpha)$ value for the AC scale was 0.81 . WE was measured using a nine item short version Utrecht WE Scale devised by Schaufeli, Bakker and Salanova [47]. A sample question for WE scale included: At my job, I feel strong and vigorous. The alpha $(\alpha)$ coefficient's value for this scale was 0.79. We adopted a 3 item EC scale from Oldham and Cummings [70]. A sample item is: This employee often comes up with original and practical ideas to improve performance. The $\alpha$ reliability for the EC scale was 0.83 . We used gender, tenure, age, and education as the control variables for this study.

\section{Results}

\subsection{Data Analysis}

For testing the hypothesized model, we applied the structural equation modeling (SEM) technique with a maximum-likelihood estimation through AMOS 25. It allowed us a complete assessment of all the studied variables with the data used for the hypothesized model [71,72]. Anderson and Gerbing's [73] 2-step approach was applied to confirm the hypotheses. Firstly, we developed a 
measurement model via confirmatory factor analysis (CFA) to confirm the model, and then the SEM technique was employed in the second step to test all path coefficients and the model fit. For model fit estimation, different fit indices containing Chi-square $\left(\chi^{2}\right)$, degrees of freedom (df), $\chi^{2} / \mathrm{df}$, incremental fit index (IFI), comparative fit indices (CFI), the standardized root mean square residual (SRMR), the Tucker-Lewis index (TLI), the non-centrality parameter (NCP), and the root mean square error of approximation (RMSEA) were utilized. The acceptable cutoff points for all the indices are exhibited in Table 1. In addition, there was a possibility of non-independent observations arising when the supervisors' evaluated their employees' creativity in our survey, and, thus, that the results reflected the leader rather than the employees that they assessed.

Table 1. Goodness of fit statistics.

\begin{tabular}{|c|c|c|c|c|}
\hline CFA Goodness of Fit Indices & Model Value & Cutoff Point & Overall Model Fit & Reference \\
\hline Normed Chi-Square ( $\left.\chi^{2} / \mathrm{df}\right)$ & 1.19 & $<3$ & Yes & Qing et al. [46] \\
\hline $\begin{array}{l}\text { Standardized Root Mean Square } \\
\text { Residual (SRMR) }\end{array}$ & 0.04 & $<0.05$ & Yes & Iacobucci [74] \\
\hline $\begin{array}{l}\text { Root Mean Square Error of } \\
\text { Approximation (RMSEA) }\end{array}$ & 0.03 & $<0.06$ & Yes & Iacobucci [74] \\
\hline Incremental Fit Measures (IFI) & 0.96 & $>0.95$ & Yes & Hair et al. [75] \\
\hline Tucker-Lewis Index (TLI) & 0.96 & $>0.95$ & Yes & Hair et al. [75] \\
\hline Comparative Fit Index (CFI) & 0.97 & $>0.95$ & Yes & Hair et al. [75] \\
\hline P. Close & 0.91 & $\begin{array}{c}>0.05 \text { and }<1 \\
>\text { Saturated model }(0.00)\end{array}$ & Yes & Byrne [76] \\
\hline Non-centrality Parameter (NCP) & 254.62 & $\begin{array}{c}<\text { independent model } \\
(4875.82)\end{array}$ & Yes & Byrne [76] \\
\hline
\end{tabular}

\subsection{Descriptive Statistics}

Means, SD, correlations, and the reliabilities of all variables are presented in Table 2. EL was significantly and positively correlated with AC $(r=0.42, p<0.01)$, WE $(r=0.23$ and $p<0.05)$ and EC $(r=0.39$ and $p<0.05)$. Both WE and EC were positively related to AC $(r=0.27, p<0.01, \mathrm{r}=0.38$, and $p<0.01$, respectively), and WE was positively correlated to worker EC $(\mathrm{r}=0.33$ and $p<0.01)$.

Table 2. Descriptive statistics, correlations, and reliabilities.

\begin{tabular}{|c|c|c|c|c|c|c|c|c|c|}
\hline \multirow{2}{*}{$\mathbf{N}=233$} & \multirow{2}{*}{ Mean } & \multirow{2}{*}{ SD } & \multicolumn{7}{|c|}{ Correlations } \\
\hline & & & 1 & 2 & 3 & 4 & 5 & 6 & 7 \\
\hline 1. Ethical leadership & 3.38 & 0.89 & $(0.83)$ & & & & & & \\
\hline 2. Affective commitment & 2.97 & 1.11 & $0.42^{* *}$ & $(0.79)$ & & & & & \\
\hline 3. Employee work engagement & 2.80 & 1.29 & $0.23^{* *}$ & $0.27^{* *}$ & $(0.77)$ & & & & \\
\hline 4. Employee creativity & 3.13 & 1.18 & $0.39^{* *}$ & $0.38^{* *}$ & $0.33^{* *}$ & $(0.81)$ & & & \\
\hline 5. Age & 31.45 & 11.23 & 0.06 & 0.09 & -0.04 & $0.11 *$ & - & & \\
\hline 6. Tenure & 5.71 & 3.97 & 0.00 & 0.02 & -0.02 & 0.01 & $0.45^{* *}$ & - & \\
\hline 7. Education & 2.91 & 0.51 & -0.03 & 0.07 & 0.07 & 0.04 & -0.07 & $0.15^{* *}$ & - \\
\hline
\end{tabular}

The square root of AVE (bold values) are shown in parenthesis demonstrating discriminant validity. ${ }^{*} p<0.05$ and ** $p<0.01$.

\subsection{Confirmatory Factor Analysis}

A confirmatory factor analysis was executed on all constructs to analyze the internal consistency, convergent, and discriminant validity (see Table 3). From the results of Table 3, we found composite reliability (CR) ranged from 0.83 to 0.90 for each factor. These values are greater than the recommended cutoff point of 0.60 and confirmed the presence of inner consistency reliability among each construct [77,78]. The values of Cronbach's $\alpha$ were also above 0.70 [79]. As per the recommendations of Hair [80], factor loadings above 0.5 are considered significant for providing convergent validity. In our study, the standardized factor loadings are ranged from 0.73 to 0.85 $(p<0.001)$. Hence, the measures did not have any issue regarding the convergent validity. To check the discriminant validity, AVE estimates were compared with the squared values of correlation between 
the constructs. As shown in Table 2, all the AVE values were greater than the squared correlations, thus the model fits the criteria for discriminant validity [81].

Table 3. Measurement model for all four factors.

\begin{tabular}{|c|c|c|c|c|c|c|}
\hline Construct & Loading & SE & $\mathrm{T}$ & $\alpha$ & AVE & CR \\
\hline Ethical leadership & & & & 0.86 & 0.69 & 0.90 \\
\hline $\begin{array}{l}\text { My supervisor conducts his/her personal life in an ethical } \\
\text { manner. }\end{array}$ & 0.85 & - & - & & & \\
\hline $\begin{array}{l}\text { My supervisor defines success not just by results but also the } \\
\text { way that they are obtained. }\end{array}$ & 0.83 & 0.045 & $18.40(* *)$ & & & \\
\hline My supervisor listens to what employees have to say. & 0.76 & 0.047 & $16.15(* * *)$ & & & \\
\hline $\begin{array}{l}\text { My supervisor disciplines employees who violate ethical } \\
\text { standards. }\end{array}$ & 0.73 & 0.044 & $16.63(* * *)$ & & & \\
\hline My supervisor makes fair and balanced decisions. & 0.81 & 0.047 & $17.04(* * *)$ & & & \\
\hline My supervisor can be trusted. & 0.83 & 0.046 & $18.13(* * *)$ & & & \\
\hline $\begin{array}{l}\text { My supervisor discusses business ethics or values with } \\
\text { employees. }\end{array}$ & 0.85 & 0.046 & $\left.18.399^{* * *}\right)$ & & & \\
\hline $\begin{array}{l}\text { My supervisor sets an example of how to do things the right } \\
\text { way in terms of ethics. }\end{array}$ & 0.79 & 0.047 & $16.79(* *)$ & & & \\
\hline My supervisor has the best interests of employees in mind. & 0.78 & 0.047 & $16.67(* * *)$ & & & \\
\hline $\begin{array}{l}\text { My supervisor when making decisions, asks "what is the } \\
\text { right thing to do?" }\end{array}$ & 0.74 & 0.049 & $15.09(* * *)$ & & & \\
\hline Affective commitment & & & & 0.81 & 0.62 & 0.84 \\
\hline $\begin{array}{l}\text { I would be happy to spend the rest of my career with this } \\
\text { organization. }\end{array}$ & 0.82 & - & - & & & \\
\hline I really feel that this organization's problems are my own. & 0.79 & 0.05 & $15.70(* * *)$ & & & \\
\hline I feel a strong sense of belonging to my organization. & 0.83 & 0.048 & $17.35(* *)$ & & & \\
\hline I feel "emotionally attached" to this organization. & 0.74 & 0.051 & $\left.14.39{ }^{* * *}\right)$ & & & \\
\hline I feel like "part of the family" at this organization. & 0.77 & 0.049 & $15.61(* *)$ & & & \\
\hline This organization has a great deal of personal meaning to me. & 0.80 & 0.050 & $16.13(* * *)$ & & & \\
\hline Work engagement & & & & 0.79 & 0.62 & 0.83 \\
\hline At my work, I feel bursting with energy. & 0.80 & - & - & & & \\
\hline At my job, I feel strong and vigorous. & 0.78 & 0.047 & $16.68(* *)$ & & & \\
\hline I am enthusiastic about my job & 0.83 & 0.045 & $18.37(* * *)$ & & & \\
\hline My job inspires me. & 0.85 & 0.045 & $18.91(* * *)$ & & & \\
\hline When I get up in the morning, I feel like going to work. & 0.79 & 0.046 & $17.17(* * *)$ & & & \\
\hline I feel happy when I am working intensely. & 0.81 & 0.047 & $17.23(* * *)$ & & & \\
\hline I am proud of the work that I do. & 0.76 & 0.044 & $17.27(* * *)$ & & & \\
\hline I am immersed in my work. & 0.74 & 0.045 & $16.44\left(^{* * *}\right)$ & & & \\
\hline I get carried away when I am working. & 0.79 & 0.047 & $\left.16.87^{* * *}\right)$ & & & \\
\hline Employee creativity & & & & 0.83 & 0.66 & 0.86 \\
\hline $\begin{array}{l}\text { This employee often comes up with original and practical } \\
\text { ideas to improve performance }\end{array}$ & 0.85 & - & - & & & \\
\hline $\begin{array}{l}\text { This employee often comes up with adaptive and practical } \\
\text { work that is useful to the organization. }\end{array}$ & 0.78 & 0.047 & $16.45(* * *)$ & & & \\
\hline $\begin{array}{l}\text { This employee develops ideas, methods, or products that are } \\
\text { both original and useful to the organization. }\end{array}$ & 0.81 & 0.048 & $17.01(* * *)$ & & & \\
\hline
\end{tabular}

$$
\text { *** } p<0.001
$$

Based on the results of CFA (demonstrated in Table 4), we found that the four-factor model delivered the best fit with a comparison to the three-factor, two-factor, and the one-factor models. We further noticed significant $(p<0.05) \chi^{2}$ differences between the four-factor model and all other alternative models. This indicated discriminant validity and reduced the possibility of CMV in the data $[67,82]$. Hence, it was concluded that the four-factor model with excellent fit indices $\left(\chi^{2}=327.34\right.$, $\mathrm{df}=265, \chi^{2} / \mathrm{df}=1.24, \mathrm{CFI}=0.96, \mathrm{IFI}=0.96, \mathrm{TLI}=0.96, \mathrm{SRMR}=0.05$, and RMSEA $=0.04$ ) was the most suitable one to be used to examine the distinctive properties of all four variables considered in this research. 
Table 4. Confirmatory factor analysis.

\begin{tabular}{|c|c|c|c|c|c|c|c|c|c|}
\hline Model & $x^{2}$ & Df & $\chi^{2} / \mathrm{df}$ & $\Delta \chi^{2}(\Delta d f)$ & CFI & IFI & TLI & SRMR & RMSEA \\
\hline 4-Factor model & 327.34 & 265 & 1.24 & - & 0.96 & 0.96 & 0.96 & 0.05 & 0.04 \\
\hline 3-Factor model $(\mathrm{EL}+\mathrm{AC})$ & 647.01 & 271 & 2.39 & $319.67(6)^{* *}$ & 0.86 & 0.86 & 0.83 & 0.07 & 0.10 \\
\hline 3-Factor model (EL + EC) & 589.97 & 273 & 2.16 & $262.63(8) * *$ & 0.89 & 0.89 & 0.89 & 0.06 & 0.08 \\
\hline 3-Factor model (AC + WE) & 801.12 & 277 & 2.89 & $473.78(12) * *$ & 0.80 & 0.81 & 0.79 & 0.07 & 0.09 \\
\hline 3-Factor model (AC + EC) & 413.45 & 276 & 1.50 & $86.11(11)^{* *}$ & 0.92 & 0.90 & 0.90 & 0.07 & 0.06 \\
\hline 2-Factor model (EL + AC + EC) & 930.98 & 283 & 3.29 & $603.64(18)^{* *}$ & 0.80 & 0.80 & 0.78 & 0.11 & 0.10 \\
\hline 2-Factor model (EL + WE + EC) & 1117.51 & 283 & 3.95 & $790.17(18)^{* *}$ & 0.78 & 0.77 & 0.77 & 0.10 & 0.13 \\
\hline 2-Factor model $(\mathrm{AC}+\mathrm{WE}+\mathrm{EC})$ & 1073.67 & 287 & 3.74 & $746.33(22) * *$ & 0.79 & 0.79 & 0.79 & 0.11 & 0.07 \\
\hline 1-Factor model & 1597.05 & 299 & 5.34 & $1269.71(34) * *$ & 0.74 & 0.73 & 0.71 & 0.13 & 0.23 \\
\hline Hypothesized model & 312.25 & 269 & 1.16 & - & 0.98 & 0.98 & 0.97 & 0.03 & 0.04 \\
\hline
\end{tabular}

EL: Ethical Leadership, AC: Affective Commitment, WE: Work Engagement and EC: Employee Creativity. ${ }^{* *} p<0.01$.

\subsection{Hypothesis Testing}

The structural modeling results indicate that the hypothesized model fit the data well $\left(\chi^{2}=312.25\right.$, $\mathrm{df}=269, \chi^{2} / \mathrm{df}=1.16, \mathrm{CFI}=0.98, \mathrm{IFI}=0.98, \mathrm{TLI}=0.97, \mathrm{SRMR}=0.03$, and RMSEA $=0.04$, see Table 4). Our study also tested the impact of control variable on EC and found positive and significant effects of gender $(\beta=0.11$ and $p<0.05)$ and tenure $(\beta=0.13$ and $p<0.05)$, while age $(\beta=0.11$ and $p>0.05)$ and education ( $\beta=0.09$ and $p>0.05)$ have insignificant effect on EC. We followed a Baron and Kenny [83] suggestion and used two step strategy to examine the hypotheses. In our study, first step of mediation is related to Hypotheses 1 and 2. We checked the direct effects of EL on both EC and WE. We also noted the fit indices $\left(\chi^{2}=299.43, \mathrm{df}=261, \chi^{2} / \mathrm{df}=1.14, \mathrm{CFI}=0.97, \mathrm{IFI}=0.97, \mathrm{TLI}=0.98\right.$, SRMR $=0.03$, and RMSEA $=0.03$ ) for these relationships. As shown in Table 5, the results of the direct effect of EL on EC (standardized $\beta=0.45, \mathrm{t}=10.97$ and $p<0.01$, see Table 5), and the direct effect of EL on WE (standardized $\beta=0.26, t=6.67$ and $p<0.01$ ) were both statistically significant. Thus Hypotheses 1 and 2 were supported.

Table 5. $\beta$ coefficients for testing Hypotheses 1 and 2.

\begin{tabular}{ccccc}
\hline Path & Standardized $\boldsymbol{\beta}$ & SE & $\mathbf{t}$ & Significance \\
\hline Ethical leadership $\rightarrow$ Employee creativity & 0.45 & 0.041 & 10.97 & $<0.01\left({ }^{* *}\right)$ \\
\hline Ethical leadership $\rightarrow$ Work engagement & 0.26 & 0.039 & 6.67 & $<0.01\left({ }^{* *}\right)$ \\
\hline & $* * p<0.01$.
\end{tabular}

In the second step, the Hypotheses 3 and 4 are tested by inspecting the four Baron and Kenny [83] conditions for mediation: (a) the independent variable has to predict the criterion variable, (b) the proposed mediator has to be predicted by the independent variable, (c) the proposed mediator predict the criterion variable, and (d), the direct path between the independent variable and the criterion variable has to decrease (preferably need to be insignificant for full mediation) when the mediator is added.

As Table 5 shows, EL fulfilled Baron and Kenny [83] first condition (a), as EL showed significant paths to WE $(\beta=0.26, p<0.01)$ and EC $(\beta=0.45, p<0.01)$. Regarding second condition of mediation, both AC and We fulfill Baron and Kenny's [83] criteria. As of Figure 2, EL significantly predicted AC $(\beta=0.51, p<0.01)$ and WE $(\beta=0.26, p<0.01)$ while in third condition, first mediator, AC predicted criterion variable WE $(\beta=0.63, p<0.01)$ and second mediator WE significantly predicted criterion variable EC $(\beta=0.49, p<0.01)$. In fourth condition, the direct relationship between EL and WE in the presence of a mediator $\mathrm{AC}$ is decreased (from $\beta=0.26$ to $\beta=0.23$ ) and is statistically significant. It provided partial mediation. Similarly, the direct relationship between EL and EC in the presence of mediators disappears and becomes insignificant ( $\beta=0.11$, see Figure 2$)$, showing full mediation effect. All these results empirically support $\mathrm{H} 3$ and $\mathrm{H} 4$. 


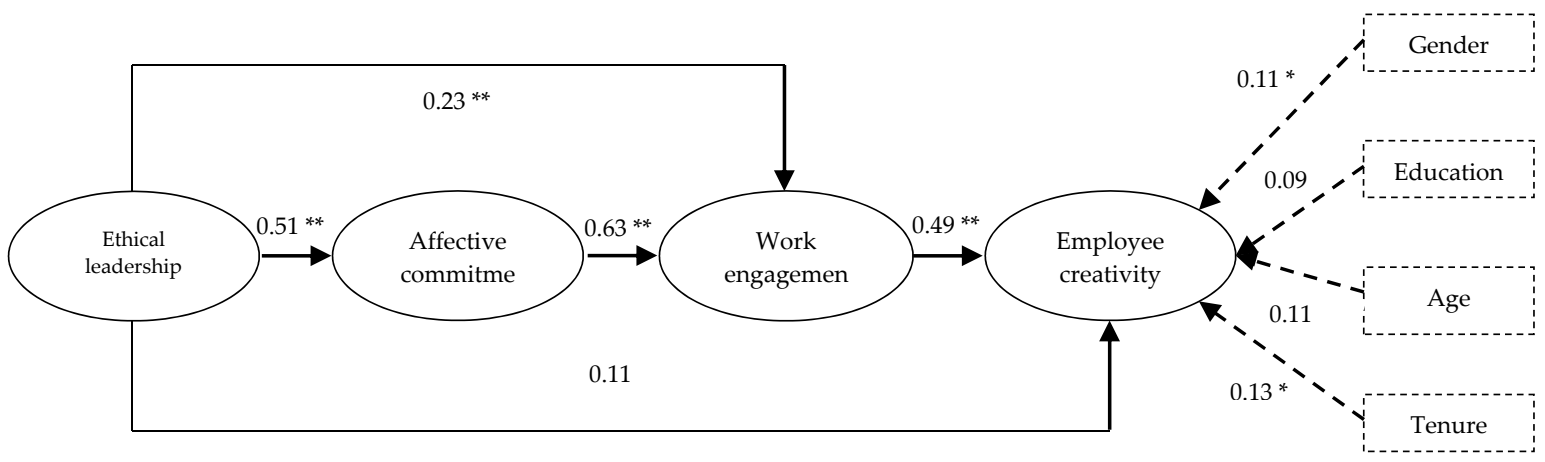

Figure 2. Structural equation modeling (SEM) results for the hypothesized model. ${ }^{* *} p<0.01$ and $* p<0.05 . \chi^{2}=312.25, \mathrm{df}=269, \chi^{2} / \mathrm{df}=1.16, \mathrm{CFI}=0.98, \mathrm{IFI}=0.98, \mathrm{TLI}=0.97, \mathrm{SRMR}=0.03$, and RMSEA $=0.04$.

We employed an additional tool to validate the indirect effects. We examined the significance of indirect effects by following the recommendations of Preacher and Hayes [84] and estimated the confidence intervals (CI) of the lower (LLCI) and upper limits (ULCI). We did percentile bootstrapping along with bias-corrected bootstrapping at 99\% confidence intervals (CI) with 10,000 boot samples (see Table 6) to measure the indirect effects [85]. The results of the bootstrapping test are shown in Table 6, which provides evidence of the significantly positive indirect effect of AC between EL and WE (indirect effect $=0.32, \mathrm{z}=8.00$ and $p<0.01$ ), and the positive and significant indirect effects of both AC and WE on the EL-EC relationship (indirect effect $=0.16, z=5.33$ and $p<0.01$ ). These results further validate mediation and support Hypotheses 3 and 4.

Table 6. Bootstrapping results for indirect effects.

\begin{tabular}{|c|c|c|c|c|c|c|c|c|}
\hline & \multirow{3}{*}{ Estimate } & \multirow{3}{*}{ Boot S.E. } & \multirow{3}{*}{ Boot Z } & \multicolumn{4}{|c|}{ Bootstrapping } & \multirow{3}{*}{$\begin{array}{l}\text { Significance } \\
\text { (2-Tailed) }\end{array}$} \\
\hline & & & & \multicolumn{2}{|c|}{ Percentile 99\% CI } & \multicolumn{2}{|c|}{ Bias-Corrected $99 \%$ CI } & \\
\hline & & & & LLCI & ULCI & LLCI & ULCI & \\
\hline \multicolumn{9}{|l|}{ Direct effects } \\
\hline $\mathrm{EL} \rightarrow \mathrm{EC}$ & 0.11 & 0.07 & 1.57 & -0.09 & 0.21 & -0.11 & 0.21 & 0.57 \\
\hline $\mathrm{EL} \rightarrow \mathrm{WE}$ & 0.23 & 0.06 & 3.83 & 0.13 & 0.26 & 0.13 & 0.26 & $0.00\left(^{* *}\right)$ \\
\hline $\mathrm{EL} \rightarrow \mathrm{AC}$ & 0.51 & 0.06 & 8.50 & 0.29 & 0.61 & 0.29 & 0.61 & $0.00(* *)$ \\
\hline $\mathrm{AC} \rightarrow \mathrm{WE}$ & 0.63 & 0.06 & 10.50 & 0.74 & 0.85 & 0.74 & 0.85 & $0.00(* *)$ \\
\hline $\mathrm{WE} \rightarrow \mathrm{EC}$ & 0.49 & 0.04 & 12.25 & 0.33 & 0.56 & 0.33 & 0.56 & $0.00(* *)$ \\
\hline \multicolumn{9}{|l|}{$\begin{array}{l}\text { Indirect } \\
\text { effects }\end{array}$} \\
\hline $\mathrm{EL} \rightarrow \mathrm{EC}$ & 0.16 & 0.03 & 5.33 & 0.7 & 0.33 & 0.07 & 0.32 & $\left.0.00{ }^{* *}\right)$ \\
\hline $\mathrm{EL} \rightarrow \mathrm{WE}$ & 0.32 & 0.04 & 8.00 & 0.25 & 0.69 & 0.25 & 0.69 & $0.00\left(^{* *}\right)$ \\
\hline \multicolumn{9}{|l|}{ Total effects } \\
\hline $\mathrm{EL} \rightarrow \mathrm{EC}$ & 0.27 & 0.06 & 4.50 & 0.07 & 0.37 & 0.07 & 0.36 & $0.00(* *)$ \\
\hline $\mathrm{EL} \rightarrow \mathrm{WE}$ & 0.55 & 0.07 & 7.86 & 0.39 & 0.65 & 0.38 & 0.65 & $0.00\left(^{* *}\right)$ \\
\hline $\mathrm{EL} \rightarrow \mathrm{AC}$ & 0.51 & 0.06 & 8.50 & 0.29 & 0.61 & 0.29 & 0.61 & $0.00(* *)$ \\
\hline $\mathrm{AC} \rightarrow \mathrm{WE}$ & 0.63 & 0.06 & 10.50 & 0.74 & 0.85 & 0.74 & 0.85 & $0.00(* *)$ \\
\hline $\mathrm{WE} \rightarrow \mathrm{EC}$ & 0.49 & 0.04 & 12.25 & 0.33 & 0.56 & 0.33 & 0.56 & $\left.0.00{ }^{* *}\right)$ \\
\hline
\end{tabular}

EL: Ethical Leadership, AC: Affective Commitment, WE: Work Engagement, EC: Employee Creativity, CI: Confidence Interval, LLCI: Lower Level Confidence Interval, and ULCI: Upper Level Confidence Interval. ${ }^{* *} p<0.01$.

\section{Discussion}

In this research, we have made a significant contribution to the existing literature on EL, AC, WE, and EC by investigating the unexplored side of the EL-EC relationship. In previous leadership studies, scholars suggested that a particular style of leadership can fortify a greatly determined staff [86]. Therefore, we realized that EL is an appropriate style to make employees more engaged and creative. Engelbrecht, Heine and Mahembe [29] argued that the qualities of ethical leaders, which includes 
trust, honesty, emotional attachment, fair decision making, and justice, encourage their followers to be highly engaged in their job. Our research findings are also consistent with those of Ali Chughtai [20], which revealed that the behavior of a leader has a meaningful effect on the level of WE and EC.

Fewer researchers have reviewed the relationship between EL and EC [20,21,25], and this is the first study to examine the influences of supervisors' EL on WE and EC in the government sector institutions. We further explored the mediating effect of AC on the association between EL and WE, as well as a multiple mediation effect of both AC and WE on the association between EL and EC. The important contribution of our work is thus the mediated model, which provides a sound theoretical basis and might be used to assess the influences of EL on EC in Chinese public sector organizations with a collectivistic culture. The results exhibited that AC plays a partial mediation role on the relationship between EL and WE, and both employees' AC and WE completely mediated the EL-EC relationship. Our findings showed that AC influences WE, which proves that when workers are affectively dedicated to the institution, they are more engaged in their work. This sense of engagement enables them to produce creative ideas, offer sensitivity to a problem, and add value to complexity [87], self-confidence, persistence [18], sustainable goal achievement, and dedication to work [88]. The results of the current research also indicated that due to the causal-chain effect, WE and EC can be improved if the employees believe that they have the ability to engage in creative work. These causal-chain effects help to establish an emotional bond between the worker and the institution, and they determine how employees' engagement is promoted to make the employees more creative.

\section{Practical Implications}

This study has some useful implications for practitioners. Firstly, this research proved ethical leadership (EL) to be an influential factor that enhances employees' level of work engagement and indicates its crucial role to establish a healthy work environment where the employees become more courageous and engaged with their organization.

Second, as the outcomes of the current research showed the indirect influence of ethical leadership on employee creativity (EC) through affective commitment (AC) and work engagement, it is imperative for the managers and the supervisors to learn and seek all possible causal-chain relationships between ethical leadership and the employees' engagement, which may enhance creative performance. Therefore, we recommend that organizations put greater emphasis on proper training and developmental programs for their leaders. As a result, the reciprocal relationships will be established between leaders and their followers, which may lead to greater commitment to the organization. Additionally, it will enable the leaders to identify the direct and indirect effects of ethical leadership in the psychological processes related to work engagement and employee creativity.

Third, to maximize the leadership effectiveness and make employees more engaged, creative, and committed, it is important for the leaders to offer organizational rewards to their employees, ensure their participation in the decision-making process, make fair decisions, and promote supervisory support.

Fourth, the Chinese context with strong roots in Confucianism is relevant to a modern Chinese society which has implemented the economic reform and open-door policy to Western countries for more than 30 years. Rapid industrialization and increased diversity in values have emerged in China. A new generation of individualistic and egalitarian Chinese has become an indispensable part of the Chinese workforce [89]. More than ever before, leaders in China should pay attention to their own moral values which may enhance employees' affective commitment, engagement, and creativity. These findings thus provide useful managerial implications that may meet these emerging needs in modern Chinese society.

Finally, the results of this study provide novel ethical implications that moral values are very important in achieving success. The executives and moral leaders must provide an ethical vision and mission, create a culture with strong shared ethical values in organizations, move beyond their self-interests and personal financial gains, and promote people's creativity, quality of products and services, and sustainable development for the well-being of individuals in organizations as a whole. 


\section{Study Limitations and Suggestions for Future Study}

There are some limitations to the present study. Firstly, the data utilized for this research was gathered from one source, and it might be the reason for the likelihood of CMV [67], even though, we administered the questionnaire in three separate waves, assured the secrecy of the responses, and randomly ordered all the questions for each survey [67]. Additionally, we applied Harman's single factor technique to test biasness and found no significant effect. The most important point is the results from the confirmatory factor analysis (CFA), which the four-factor model had the best-fitted indices as compared to the other models with significant $\chi^{2}$ differences $(p<0.05)$. It provided strong evidence of lower CMV effects $[67,90]$. However, we do acknowledge that to prevent the issues caused by CMV, future studies need to apply other methods of employees' behaviors.

Second, our research was derived from the theories proposed in Western countries, and we obtained data and evaluated the proposed model in the context of Chinese public sector organizations. Even though earlier research had confirmed the relationships between ethical leadership and employee creativity $[44,65]$, no research has been conducted using employee affective commitment and work engagement as potential mediators. Therefore, the results of this study should be applied cross-culturally, and the replication of our findings will provide fruitful outcomes.

Third, the fact that study participants were recruited from an alumni database brings into question the extent to which their views represent those of others in the organization's participants were employed. However, given the sensitive setting of our research, the Chinese public sector, and the sensitive nature of the questions related to ethical leadership and employee creativity, we feel contacting the participants directly allowed us to reduce social desirability bias.

Fourthly, we collected our sample from the eastern China region. To generalize the validity of our results, future researchers need to test our model empirically using samples from other regions and other Asian cultures. More research is needed in this direction.

Finally, our study could be repeated under different industry contexts to examine the causal relationships between ethical leadership and employee creativity in other businesses. Although we used structural equation modeling to carry out a simultaneous examination of our entire proposed model in the public sector, the results still need to be taken cautiously. We suggest that future research could address this issue by obtaining data from experimental and longitudinal research in different industries to strengthen the causal relationship between ethical leadership and employee creativity with different mediators and moderators.

Author Contributions: Conceptualization: M.A.; methodology: M.A., and H.S.; validation: J.H. and M.Q.; formal analysis: M.A.; investigation: M.A., M.Q., J.H. and H.S.; resources: M.Q. and J.H.; data curation: M.Q. and J.H.; writing-original draft preparation: M.A.; writing—review and editing: M.A., M.Q., J.H. and H.S.; supervision: M.Q.; funding acquisition: J.H.

Funding: The study receives no external funding.

Conflicts of Interest: The authors declare no conflict of interest.

\section{Abbreviations}

EL ethical leadership

AC affective commitment

WE $\quad$ work engagement

EC employee creativity 


\section{References}

1. Singh, S.K.; Burgess, T.F.; Heap, J.; Almatrooshi, B.; Farouk, S. Determinants of organizational performance: a proposed framework. Intl. J. Prod. Perf. Manag. 2016, 65, 844-859.

2. Edwards-Schachter, M.; García-Granero, A.; Sánchez-Barrioluengo, M.; Quesada-Pineda, H.; Amara, N. Disentangling competences: Interrelationships on creativity, innovation and entrepreneurship. Think. Ski. Creat. 2015, 16, 27-39. [CrossRef]

3. Hirst, G.; Van Knippenberg, D.; Zhou, J. A Cross-Level Perspective on Employee Creativity: Goal Orientation, Team Learning Behavior, and Individual Creativity. Acad. Manag. J. 2009, 52, 280-293. [CrossRef]

4. McGrath, R.G.; Gourlay, A. The End of Competitive Advantage: How to Keep Your Strategy Moving as Fast as Your Business; Harvard Business Review Press: Brighton, UK, 2013.

5. Lozano, R. Creativity and organizational learning as means to foster sustainability. Sustain. Dev. 2014, 22, 205-216. [CrossRef]

6. Amabile, T.M.; Pratt, M.G. The dynamic componential model of creativity and innovation in organizations: Making progress, making meaning. Res. Organ. Behav. 2016, 36, 157-183. [CrossRef]

7. Williams, L.K.; McGuire, S.J. Economic creativity and innovation implementation: The entrepreneurial drivers of growth? Evidence from 63 countries. Small Bus. Econ. 2010, 34, 391-412. [CrossRef]

8. Sosik, J.J.; Chun, J.U.; Ete, Z.; Arenas, F.J.; Scherer, J. Examining How Leader Character Strengths and Ethical Leadership Relate To Leader Outcomes. Acad. Manag. Proc. 2018, 2018. [CrossRef]

9. Brown, M.E.; Treviño, L.K. Ethical leadership: A review and future directions. Leadersh. Q. 2006, 17, 595-616. [CrossRef]

10. Toor, S.-U.-R.; Ofori, G. Ethical Leadership: Examining the Relationships with Full Range Leadership Model, Employee Outcomes, and Organizational Culture. J. Bus. Ethics 2009, 90, 533-547. [CrossRef]

11. Newman, A.; Allen, B.; Miao, Q. I can see clearly now: The moderating effects of role clarity on subordinate responses to ethical leadership. Pers. Rev. 2015, 44, 611-628. [CrossRef]

12. Newman, A.; Kiazad, K.; Miao, Q.; Cooper, B. Examining the cognitive and affective trust-based mechanisms underlying the relationship between ethical leadership and organisational citizenship: A case of the head leading the heart? J. Bus. Ethics 2014, 123, 113-123. [CrossRef]

13. Strom, D.L.; Sears, K.L.; Kelly, K.M. Work engagement: The roles of organizational justice and leadership style in predicting engagement among employees. J. Leadersh. Organ. Stud. 2014, 21, 71-82. [CrossRef]

14. Kompaso, S.M.; Sridevi, M.S. Employee Engagement: The Key to Improving Performance. Int. J. Bus. Manag. 2010, 5, 89. [CrossRef]

15. Blomme, R.J.; Kodden, B.; Beasley-Suffolk, A. Leadership theories and the concept of work engagement: Creating a conceptual framework for management implications and research. J. Manag. Organ. 2015, 21, 125-144. [CrossRef]

16. Scott, G.; Leritz, L.E.; Mumford, M.D. The effectiveness of creativity training: A quantitative review. Creat. Res. J. 2004, 16, 361-388. [CrossRef]

17. Hon, A.H.; Lui, S.S. Employee creativity and innovation in organizations: Review, integration, and future directions for hospitality research. Int. J. Contemp. Hosp. Manag. 2016, 28, 862-885. [CrossRef]

18. George, J.M. 9 Creativity in Organizations. Acad. Manag. Ann. 2007, 1, 439-477. [CrossRef]

19. Ahmad, I.; Gao, Y. Ethical leadership and work engagement: The roles of psychological empowerment and power distance orientation. Manag. Decis. 2018, 56, 1991-2005. [CrossRef]

20. Ali Chughtai, A. Can ethical leaders enhance their followers' creativity? Leadership 2016, 12, $230-249$. [CrossRef]

21. Feng, J.; Zhang, Y.; Liu, X.; Zhang, L.; Han, X. Just the right amount of ethics inspires creativity: A cross-level investigation of ethical leadership, intrinsic motivation, and employee creativity. J. Bus. Ethics 2018, 153, 645-658. [CrossRef]

22. Blau, P.M. Exchange and Power in Social Life; Transaction Publishers: Piscatway, NJ, USA, 1964. [CrossRef]

23. Bormann, K.C. Linking daily ethical leadership to followers' daily behaviour: The roles of daily work engagement and previous abusive supervision. Eur. J. Work Organ. Psychol. 2017, 26, 1-11. [CrossRef]

24. Demirtas, O.; Akdogan, A.A. The effect of ethical leadership behavior on ethical climate, turnover intention, and affective commitment. J. Bus. Ethics 2015, 130, 59-67. [CrossRef] 
25. Chen, A.S.-Y.; Hou, Y.-H. The effects of ethical leadership, voice behavior and climates for innovation on creativity: A moderated mediation examination. Leadersh. Q. 2016, 27, 1-13. [CrossRef]

26. Dorfman, P.; Javidan, M.; Hanges, P.; Dastmalchian, A.; House, R. GLOBE: A twenty year journey into the intriguing world of culture and leadership. J. World Bus. 2012, 47, 504-518. [CrossRef]

27. Hofstede, G. Cultural constraints in management theories. Acad. Manag. Perspect. 1993, 7, 81-94. [CrossRef]

28. Resick, C.J.; Martin, G.S.; Keating, M.A.; Dickson, M.W.; Kwan, H.K.; Peng, C. What Ethical Leadership Means to Me: Asian, American, and European Perspectives. J. Bus. Ethics 2011, 101, 435-457. [CrossRef]

29. Engelbrecht, A.S.; Heine, G.; Mahembe, B. Integrity, ethical leadership, trust and work engagement. Leadersh. Organ. Dev. J. 2017, 38, 368-379. [CrossRef]

30. Javidan, M.; Carl, D.E. East Meets West: A Cross-Cultural Comparison of Charismatic Leadership among Canadian and Iranian Executives. J. Manag. Stud. 2004, 41, 665-691. [CrossRef]

31. Brown, M.E.; Treviño, L.K.; Harrison, D.A. Ethical leadership: A social learning perspective for construct development and testing. Organ. Behav. Hum. Decis. Process. 2005, 97, 117-134. [CrossRef]

32. Ferrell, O.C.; Fraedrich, J. Business Ethics: Ethical Decision Making \& Cases; Cengage Learning: Boston, MA, USA, 2016.

33. Mayer, D.M.; Kuenzi, M.; Greenbaum, R.L. Examining the Link between Ethical Leadership and Employee Misconduct: The Mediating Role of Ethical Climate. J. Bus. Ethics 2010, 95, 7-16. [CrossRef]

34. Bandura, A.; Walters, R.H. Social Learning Theory; Learning Theory: New York, NY, USA, 1977.

35. Mayer, D.M.; Kuenzi, M.; Greenbaum, R.; Bardes, M.; Salvador, R.B. How low does ethical leadership flow? Test of a trickle-down model. Organ. Behav. Hum. Decis. Process. 2009, 108, 1-13. [CrossRef]

36. Greenberg, J. A Taxonomy of Organizational Justice Theories. Acad. Manag. Rev. 1987, 12, 9-22. [CrossRef]

37. Colquitt, J.A. On the dimensionality of organizational justice: A construct validation of a measure. J. Appl. Psychol. 2001, 86, 386-400. [CrossRef] [PubMed]

38. Obiora, J.N.; Okpu, T. Opportunity for innovation and organizational citizenship behaviour in the Nigerian hospitality industry. Eur. J. Hosp. Tour. Res. 2015, 3, 1-13.

39. Northouse, P.G. Leadership: Theory and Practice; Sage Publications: Shawzend Oaks, CA, USA, 2018.

40. Piccolo, R.F.; Greenbaum, R.; Hartog, D.N.D.; Folger, R. The relationship between ethical leadership and core job characteristics. J. Organ. Behav. 2010, 31, 259-278. [CrossRef]

41. Iqbal, N.; Bhatti, W.A.; Zaheer, A. Corporate ethical values, group creativity, job commitment and performance: the effect of work response on work context. Manag. Mark. 2013, 8, 79-94.

42. Kouzes, J.M.; Posner, B.Z. The Leadership Practices Inventory (LPI): Participant's Workbook; John Wiley \& Sons: Hoboken, NJ, USA, 2003; Volume 47.

43. Benni, W.; Nanus, B. Leaders (Collins Business Essentials, New York); HarperBusiness Publisher: New York, NY, USA, 2007.

44. Gu, Q.; Tang, T.L.-P.; Jiang, W. Does moral leadership enhance employee creativity? Employee identification with leader and leader-member exchange (LMX) in the Chinese context. J. Bus. Ethics 2015, 126, 513-529. [CrossRef]

45. Stouten, J.; van Dijke, M.; De Cremer, D.; Eisenbeiß, S.A.; Giessner, S.R.; Cornelis, I.; Van Hiel, A.; Wisse, B.; Rus, D.; Camps, J. Special Issue: Leading with Integrity: Current Perspectives on the Psychology of Ethical Leadership. J. Pers. Psychol. 2012, 11, 204-208.

46. Qing, M.; Asif, M.; Hussain, A.; Jameel, A. Exploring the impact of ethical leadership on job satisfaction and organizational commitment in public sector organizations: The mediating role of psychological empowerment. Rev. Manag. Sci. 2019, 1-28. [CrossRef]

47. Schaufeli, W.B.; Bakker, A.B.; Salanova, M. The measurement of work engagement with a short questionnaire: A cross-national study. Educ. Psychol. Meas. 2006, 66, 701-716. [CrossRef]

48. Mauno, S.; Kinnunen, U.; Ruokolainen, M. Job demands and resources as antecedents of work engagement: A longitudinal study. J. Vocat. Behav. 2007, 70, 149-171. [CrossRef]

49. Belschak, F.D.; Hartog, D.N.D. Work Engagement and Machiavellianism in the Ethical Leadership Process. J. Bus. Ethics 2012, 107, 35-47.

50. Chen, C.-F.; Kao, Y.-L. Moderating effects of work engagement and job tenure on burnout-performance among flight attendants. J. Air Transp. Manag. 2012, 25, 61-63. [CrossRef]

51. Demirtas, O. Ethical leadership influence at organizations: Evidence from the field. J. Bus. Ethics 2015, 126, 273-284. [CrossRef] 
52. Brandebo, M.F.; Nilsson, S.; Larsson, G. Leadership: Is bad stronger than good? Leadersh. Organ. Dev. J. 2016, 37, 690-710. [CrossRef]

53. Macey, W.H.; Schneider, B.; Barbera, K.M.; Young, S.A. Employee Engagement: Tools for Analysis, Practice, and Competitive Advantage; Wiley: Hoboken, NJ, USA, 2009.

54. Woodman, R.W.; Sawyer, J.E.; Griffin, R.W. Toward a Theory of Organizational Creativity. Acad. Manag. Rev. 1993, 18, 293-321. [CrossRef]

55. Rhoades, L.; Eisenberger, R.; Armeli, S. Affective commitment to the organization: The contribution of perceived organizational support. J. Appl. Psychol. 2001, 86, 825-836. [CrossRef]

56. Detert, J.R.; Edmondson, A.C. Implicit Voice Theories: Taken-for-Granted Rules of Self-Censorship at Work. Acad. Manag. J. 2011, 54, 461-488. [CrossRef]

57. Meyer, J.P.; Allen, N.J. Commitment in the Workplace: Theory, Research, and Application; Sage Publications: Shawzend Oaks, CA, USA, 1997.

58. Luchak, A.A.; Gellatly, I.R. A comparison of linear and nonlinear relations between organizational commitment and work outcomes. J. Appl. Psychol. 2007, 92, 786-793. [CrossRef]

59. Binnewies, C.; Ohly, S.; Niessen, C. Age and creativity at work: The interplay between job resources, age and idea creativity. J. Manag. Psychol. 2008, 23, 438-457. [CrossRef]

60. Licata, J.W.; Mowen, J.C.; Harris, E.G.; Brown, T.J. On the Trait Antecedents and Outcomes of Service Worker Job Resourcefulness: A Hierarchical Model Approach. J. Acad. Mark. Sci. 2003, 31, 256-271. [CrossRef]

61. Asif, M.; Jameel, A.; Hussain, A.; Hwang, J.; Sahito, N. Linking Transformational Leadership with Nurse-Assessed Adverse Patient Outcomes and the Quality of Care: Assessing the Role of Job Satisfaction and Structural Empowerment. Int. J. Environ. Res. Public Health 2019, 16, 2381. [CrossRef]

62. Amabile, T.M.; Barsade, S.G.; Mueller, J.S.; Staw, B.M. Affect and Creativity at Work. Adm. Sci. Q. 2005, 50, 367-403. [CrossRef]

63. Avery, D.R.; McKay, P.F.; Wilson, D.C. Engaging the aging workforce: The relationship between perceived age similarity, satisfaction with coworkers, and employee engagement. J. Appl. Psychol. 2007, 92, 1542-1556. [CrossRef]

64. Manzoor, F.; Wei, L.; Nurunnabi, M.; Subhan, Q.A.; Shah, S.I.A.; Fallatah, S. The Impact of Transformational Leadership on Job Performance and CSR as Mediator in SMEs. Sustainability 2019, 11, 436. [CrossRef]

65. Ma, Y.; Cheng, W.; Ribbens, B.A.; Zhou, J. Linking Ethical Leadership to Employee Creativity: Knowledge Sharing and Self-Efficacy as Mediators. Soc. Behav. Pers. Int. J. 2013, 41, 1409-1419. [CrossRef]

66. Brislin, R.W. Understanding Culture's Influence on Behavior; Harcourt Brace Jovanovich College Publishers: San Diego, CA, USA, 1993.

67. Podsakoff, P.M.; MacKenzie, S.B.; Lee, J.-Y.; Podsakoff, N.P. Common method biases in behavioral research: A critical review of the literature and recommended remedies. J. Appl. Psychol. 2003, 88, 879-903. [CrossRef] [PubMed]

68. Cheung, G.W.; Rensvold, R.B. Evaluating Goodness-of-Fit Indexes for Testing Measurement Invariance. Struct. Equ. Model. A Multidiscip. J. 2002, 9, 233-255. [CrossRef]

69. Meyer, J.P.; Allen, N.J.; Smith, C.A. Commitment to organizations and occupations: Extension and test of a three-component conceptualization. J. Appl. Psychol. 1993, 78, 538-551. [CrossRef]

70. Oldham, G.R.; Cummings, A. Employee Creativity: Personal and Contextual Factors at Work. Acad. Manag. J. 1996, 39, 607-634.

71. Jöreskog, K.G.; Sörbom, D. Recent Developments in Structural Equation Modeling. J. Mark. Res. 1982, 19, 404. [CrossRef]

72. Jameel, A.; Asif, M.; Hussain, A. Good Governance and Public Trust: Assessing the Mediating Effect of E-Government in Pakistan. Lex Localis J. Local Self-Gov. 2019, 17, 299-320. [CrossRef]

73. Anderson, J.C.; Gerbing, D.W. Structural equation modeling in practice: A review and recommended two-step approach. Psychol. Bull. 1988, 103, 411-423. [CrossRef]

74. Iacobucci, D. Structural equations modeling: Fit Indices, sample size, and advanced topics. J. Consum. Psychol. 2010, 20, 90-98. [CrossRef]

75. Hair, J.F. Multivariate Data Analysis: An Overview. In International Encyclopedia of Statistical Science; Springer: Berlin/Heidelberg, Germany, 2011; pp. 904-907. [CrossRef]

76. Byrne, B.M. Structural Equation Modeling with AMOS: Basic Concepts, Applications, and Programming; Routledge: Abington, UK, 2016. 
77. Fornell, C.; Larcker, D.F. Evaluating Structural Equation Models with Unobservable Variables and Measurement Error. J. Mark. Res. 1981, 18, 39-50. [CrossRef]

78. Bagozzi, R.P.; Yi, Y. On the evaluation of structural equation models. J. Acad. Mark. Sci. 1988, 16, 74-94. [CrossRef]

79. Nunnally, J.C.; Bernstein, I.H. Psychometric Theory; Tata McGraw-Hill Ed.: New Delhi, India, 2010.

80. Hair, J.F. Multivariate Data Analysis; Prentice Hall: Upper Saddle River, NJ, USA, 2010. [CrossRef]

81. Shaffer, J.A.; DeGeest, D.; Li, A. Tackling the Problem of Construct Proliferation: A Guide to Assessing the Discriminant Validity of Conceptually Related Constructs. Organ. Res. Methods 2016, 19, 80-110. [CrossRef]

82. Podsakoff, P.M.; MacKenzie, S.B.; Podsakoff, N.P. Sources of Method Bias in Social Science Research and Recommendations on How to Control It. Annu. Rev. Psychol. 2012, 63, 539-569. [CrossRef] [PubMed]

83. Baron, R.M.; Kenny, D.A. The moderator-mediator variable distinction in social psychological research: Conceptual, strategic, and statistical considerations. J. Pers. Soc. Psychol. 1986, 51, 1173-1182. [CrossRef]

84. Preacher, K.J.; Hayes, A.F. Asymptotic and resampling strategies for assessing and comparing indirect effects in multiple mediator models. Behav. Res. Methods 2008, 40, 879-891. [CrossRef]

85. Taylor, A.B.; MacKinnon, D.P.; Tein, J.-Y. Tests of the three-path mediated effect. Organ. Res. Methods 2008, 11, 241-269. [CrossRef]

86. Bakker, A.B.; Albrecht, S.L.; Leiter, M.P. Key questions regarding work engagement. Eur. J. Work. Organ. Psychol. 2011, 20, 4-28. [CrossRef]

87. Dhar, R.L. Ethical leadership and its impact on service innovative behavior: The role of LMX and job autonomy. Tour. Manag. 2016, 57, 139-148. [CrossRef]

88. Engelbrecht, A.S.; Heine, G.; Mahembe, B. The influence of ethical leadership on trust and work engagement: An exploratory study. SA J. Ind. Psychol. 2014, 40,1-9. [CrossRef]

89. Zeng, R.; Greenfield, P.M. Cultural evolution over the last 40 years in China: Using the Google Ngram Viewer to study implications of social and political change for cultural values. Int. J. Psychol. 2015, 50, 47-55. [CrossRef]

90. Podsakoff, P.M.; Organ, D.W. Self-Reports in Organizational Research: Problems and Prospects. J. Manag. 1986, 12, 531-544. [CrossRef] 